\title{
The Myers-Briggs Type Indicator As A Tool To Facilitate Learning Outcomes For Team Building In The Classroom
}

Priscilla Berry, (pberry1@ju.edu), Jacksonville University

Cindy Wood, Jacksonville University

Barry Thornton, Jacksonville University

\begin{abstract}
Globalization and domestic competition are forcing businesses to rethink the human resources utilization process, and one method for considering again this challenge is creating a team culture. One key to this process for human resources development is the understanding of how to create the most successful teams. The use of the Myers-Briggs Type Indicator (MBTI) is a tool often used by business to achieve the goals of building work teams. College business majors must be introduced to the MBTI and to the dynamics of team building as a measurable skill necessary for their work environment. This research focuses on college classes in business communications, the directed study of the MBTI, and the heterogeneous mix of type in teams necessary for high learning outcomes. Specific pedagogical directions are provided for two team-building projects in writing, research, and oral presentation to small groups, thus meeting multiple course objectives.
\end{abstract}

Key Words: Teambuilding, Myers-Briggs Type Indicator, Business Communications, Team Projects, Human Resource Development, AACSB Grading Rubrics for Teambuilding

\section{INTRODUCTION}

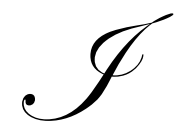

$\mathrm{n}$ the late eighties, I used the Myer-Briggs Type Indicator (MBTI) as a tool in my teambuilding workshops and seminars for several major corporations. My emphasis was on how the MBTI could help working professionals improve their communication skills by understanding the varying styles of perceiving and processing information. Use of the MBTI produced dramatic results in breaking down communication barriers, especially between departments that needed more collaboration to facilitate favorable outcomes on strategically volatile projects. These corporations had much at stake, and the realization that success for a particular project did not rest solely on their perception of communication was revelatory.

Once the MBTI was introduced and employees were trained in the use of this information, they were amazed. It was a successful exercise, and the use of the instrument produced dramatic results in breaking down communication barriers, especially between departments where little or no communication networks were in place, prior to the testing. There was little lateral communication, and the organization relied on the bureaucratic methods of top down communications. The implementation of the information from the MBTI helped to create a culture of trust and aid in the establishment of a more flat and open communication system.

During the same time, I was teaching four sections of Business Communications at a small, four-year liberal arts college where I introduced the MBTI to the students as a relevant instrument for communication in the business world. While I was sold on the value of the MBTI in helping corporations communicate more effectively, I did not see the same level of value in the classroom. I administered the MBTI to students, and we discussed the 
relevance of the instrument for communications, but I did not grasp the impact of actually implementing its use in the classroom. The MBTI was taught mostly as a concept, but not as a skill. That was then and this is now.

The business arena today expects that students with a Business degree demonstrate an awareness of interpersonal skills with a working knowledge of team dynamics. All employees, in any of the professions, are now required to work as a team and to display greater understanding for individual differences to meet corporate objectives.

These skills were historically perceived as "soft skills" in the business and academic arenas, and, we, in the college of business, consistently relied on Educational Testing Service (ETS) to validate our learning outcomes. Times have changed, especially with demand for the seal of approval from the Association for Accreditation of Collegiate Schools of Business (AACSB) and the other accrediting agencies for colleges. My on- going relationship within the business community and the academic world provides a link on how the MBTI can be effectively used in the classroom to bring about the same high level of team dynamics as required in the business arena.

This research and explication of the MBTI are intended for an easy and hands-on assignment for the classroom instructor. It sets forth a procedure that will make teamwork in the classroom easier and forecast stronger outcomes. The specific project contains not only the MBTI, but also uses a research assignment, a writing assignment, and an oral presentation as team projects that accomplish more than one course objective.

Part of the reason for the success in business for the MBTI is the ability of the employer to provide work time for employees to attend a MBTI workshop, which not only administers the MBTI to employees but also provides feedback sessions tailored to meeting their communication needs. Employees are able to see instant positive applications using the MBTI resulting in change in the workplace. For students to take the MBTI as seriously in class performance, there must be a mechanism for the teacher to tie the grade of the student to the team performance (performance in the team not just the outcome), as the employer can do for teamwork on the job. We must move away from the concept that the classroom represents the study of theory only, intended for practical application later. The students should have concrete experiences now, especially in the area of teamwork (Coby and Lewis, 2000).

This research provides a mechanism for grading teamwork and presents a formula for teaching team dynamics and creating teams in the classroom that will not require excess study or complete mastery of some of the complexities of the MBTI.

\section{BACKGROUND}

The mother-daughter pair, Katherine Cook Briggs and Isabelle Briggs Myers, who created this instrument, now translated into more than 20 languages, and more widely used in business than any other single tool for facilitating people- outcomes in corporations, followed closely the work of Swiss psychologist, Carl Jung, and his analysis of psychological type. Jung was a student of Freud and basically, Freud believed that as individuals we have more differences from each other and only some similarities. Jung, his student, believed the opposite, that we have more similarities than differences. Katherine and Isabelle, following Jung's theory, began their research in the 1920's to type these differences and show the similarities. This first premise of the MBTI instrument, the need for understanding, sets forth a beginning goal and a major challenge, in and of itself. The MBTI simply identifies 16 personality types and shows the process by which a person perceives and evaluates information, considering four dimensions of personality: Extroversion-Introversion, Intuiting-Sensing, Thinking- Feeling, and JudgingPerceiving. The combinations for the $\mathbf{1 6}$ types are found in the appendix (Item 1). The four domains are the places people prefer to live and operate from, and these preferences determine how the individual performs and perceives the world.

An examination of the literature on use of the MBTI suggests that team building is enhanced by personality diversity within the team (Hammer\& Huszczo, 1996). The diversity needed within the team as noted by Dilworth and Richter (1995) includes perceptual preferences and cognitive orientation to guard against perceptual errors. In 
1974, Myers and McCaulley first used the MBTI as a tool to improve the effectiveness of teams (Myers, McCulley, Ouenk \& Hammer, 1998). In their manual Myers and McCaulley state: "the basic assumptions underlying using the MBTI with teams remain the same. Knowledge of individual differences will help teams identify the particular talents and gifts that each member brings to his or her task: and this knowledge can help reduce conflict by reframing potential sources of misunderstanding as natural individual difference" (p.348). In the business world today, the biggest missing element in teamwork is trust, and teaching about differences in personality domains in the classroom can be a small part of recreating trust through understanding the gifts of personality types.

Extrovert and Introvert: Orientation to the world. Extroverts are energized by the world of people and things, and prefer not to be isolated from people. Introverts, on the other hand, prefer time alone and need time to recharge their batteries. They are energized by the world of concepts and ideas. Possible conflict occurs when the extrovert perceives the introvert as too reserved, self-absorbed, aloof, and thinking without ever acting and/or when the introvert perceives the extrovert as too talkative, superficial, intrusive, and acting without ever thinking.

Sensing and Intuitive: Perception of the world. Sensing individuals perceive information by their sense organs; they use the five senses. They are drawn to the world of fact and the need to be precise and concrete. They are practical and demand hard data that deal in specific information, and they usually like information broken down into components. They like to develop a single idea in depth. The intuitive person sees the world of possibilities. They are imaginative, look to the future, and always like to explore what is new. Possible conflict occurs when the subject or the challenge of change occurs. The sensor may see the Intuitives as unrealistic, flighty, and living in the future. The Intuitives may see the sensor as unimaginative, boring, lacking vision and clinging to the present, the known.

Thinking and Feeling: Judgment about the world. The thinking individual is always concerned with fairness. They tend to be scientific in their approach, and use analysis, hard facts, and logic to reach a conclusion. The Feeler is most concerned with human values, and how other people in the team feel. They are emotional about feelings; but not necessarily emotional people. Possible conflict occurs when the Thinker is viewed by the Feeler as too impersonal, insensative, critical, and inconsiderate of how others may feel. The Thinker may view the feeler as overly sensitive, irrational, and needing to please others too much.

Perceiving and Judging: Attitude to the world and people. The Perceiver is open to the world, to change and is always curious. They expect the unexpected, and wait as long as possible to make a decision. Judgers make decisions quickly and like a schedule, and they want to do things quickly. Possible conflict occurs when the Perceiver sees the Judger as too rigid, controlling, and jumping to decisions with too little information or when the Judger sees a Perceiver as disorganized, unreliable, procrastinating, and incapable of making decisions without more information. The major areas of conflict between these types are over time and decision-making.

\section{THE TEST}

The career services department of your college or school can administer the MBTI, and there are two basic versions of the MBTI. For purposes of this research, I used form M, which was administered online, and the individual results were given to each student. The longer version, 126 question form $\mathrm{G}$, is reported to be the most reliable (Brightman, ND). However, the 96-question form $\mathrm{M}$ was easy to use and produced accurate results.

The students complete the test online and within a few days receive their profile along with other useful resources. The information that it provided to the test taker with this form provides a general initiation, and a sample profile is included in the appendix (Item 2). The career services department, in this case, absorbed the cost of administering this test, which is $\$ 9$ per students. The information from the Center for Applied Psychological Type (CAPT) provides a spectrum that accompanies the type delineation and shows the student a scale for their preference. This avoids the pigeon- hole effect and reveals the variance in type preference. Make sure, whatever method you use, that a common and valid vocabulary can be established through the administering of the test. All team members should have a common understanding of the terminology. The MBTI is by far the most reliable instrument for determining personality type and the one the students will encounter most often in the business world. 
The test should be administered at the beginning of the semester and the results can be utilized throughout the semester. The first goals for the instrument's use in the classroom are the following:

- Understanding how the individual finds energy and how they focus their attention (extraversion or introversion)

- Knowing how the individual chooses to take in and process information (sensing and intuition)

- $\quad$ Realizing how the individual prefers to make decisions (thinking or feeling)

- $\quad$ Learning the way an individual relates to the external world (judging or perceiving)

\section{THE PROCESS OF FORMING TEAMS}

The first thing as instructors that you need to do is take the test yourself. The CAPT, which purchased the instrument in 1985 and has the largest data bank on testing results, reports that the majority of university faculty are introverts, and the majority of undergraduate students are extraverts. These results indicate that $56 \%$ to $58 \%$ of 16,000 freshman students at three state universities were extraverted. The data also shows that Phi Betta Kappas were over $65 \%$ introverts, and leaders on college campuses were more than $85 \%$ extroverts. While this is not surprising data, it is important that we remember this information when forming teams, and when we, as instructors, create assignments for the teams. Assigning individuals to teams according to type insures that the team has diversity and gives the instructor more control over outcomes.

Every process of communication must begin with knowing ourselves, and it is that understanding that makes us more confident. Students, who read the profiles for the first time, express relief that someone actually understands some things about them. The second realization, that other members of their class, their team, are different and, in fact, do not "see" the world as they do, is the beginning of the most important process of honoring difference.

One exercise that is very helpful is to allow students to share information about themselves informally in the team. So much information is provided in the feedback on the type from CAPT that this is an easy and fun assignment. One of the strongest motivations, outside of the grade, is that mastery of this information provides a skill that will allow the student to fit in, which is a basic need of the human condition. To this end, the desire to make the teamwork successful becomes also a part of the need to fit into the team. Another obvious value is the knowledge and the acknowledgement of the different personality types that contribute to more successful problem solving within the team (Bayne, 1995) (Varvel, et al., 2004).

While there is much attention in current research to types in teamwork, there is not complete agreement on a particular composition that produces success every time. Factors of intelligence and situation must be included in any evaluation of group dynamics (Neuman, et al., 1999). Diversity issues of gender and ethnicity must be reconciled in the structuring of the teams. These areas are not the subject of this research. There is general agreement across the major research that personality is a key factor in team performance. There is also disagreement in some of the research. For example, Culp and Smith used a study by Blaylock that finds "that project teams with complementary preferences for taking in information and making judgments outperformed teams where all of the team members had the same preference (Culp \& Smith, 2001). Complementary preferences for information gathering would require a balance in the Sensing and Intuitive ( $\mathrm{S}$ and $\mathrm{N}$ ) domains in the team composition. The point is that diversity is required to have the highest functioning teams. Although, for example, the $\mathrm{S}$ and $\mathrm{N}$ have the most conflict in a group process, you cannot have a team with all $\mathrm{S}$ or all $\mathrm{N}$. The perspectives would be too much the same and much would be overlooked in gathering the information needed for the whole picture.

Muschinsky and Monahan (1987) proposed a "A supplementary model of person-environment fit [that] suggests that job performance is improved when team members possess characteristics that are similar to other individuals on the team" ( $p$ 269). This research by Muschinsky and Monahan varies some from Blaylock and suggests that work product is increased with similar types grouped into a team. While the two studies seem to indicate the opposite, the reality is that they are saying the same thing. You must have some similarities for 
common ground for communications to occur and yet, there has to be diversity for the whole picture to emerge. Heterogeneous groups are preferred with strict attention to type strengths when formed.

The most effective teams must have a healthy component of $\mathrm{E}$ to promote intra-team communication; the $\mathrm{E}$ is a natural communicator. If you have a team with too many of the I, the work will not move forward and certainly not quickly. The I may be smart and a capable student/worker, but he or she just will not initiate enough to organize or communicate with other team members. The I types make a strong record keeper; they pay attention when others are talking and can take note of the process.

The best leaders are the ESTJ or the ENTJ depending on the project. The sensing leader is best if there is nothing new to think, just organization and communication, but if the project calls for new thinking then the intuitive leader is best. If the team has all $\mathrm{E}$ types, the team will experience confusion because the Es all need to talk (at the same time) and will interrupt the other to speak.

In the domains of $\mathrm{S}$ and $\mathrm{N}$, there is need for balance in assigning type in the team, and there is the greatest chance for conflict between the $\mathrm{S}$ and the $\mathrm{N}$. This is where dialogue is needed when teams are formed; when team members can forecast problem areas, they can plan for conflict resolution. For the extreme $\mathrm{S}$ and $\mathrm{N}$ expect conflict and prepare. Sensing types can easily perceive the facts and can easily communicate to other members of the team. Sensing types make strong facilitators in the group. Intuitives develop complex ideas that are more difficult to express, and require more listening.

In the domains of $\mathrm{T}$ and $\mathrm{F}$, the thinking type is quick to make judgments and to verbalize the judgments, and the feeling type may not express their thoughts because they are afraid of hurt feelings. The feelers make the best harmonizer because this is their natural domain. They are the most capable of helping the team reach the trust level of communication. Group cohesion is most impacted by thinking and feeling types. The thinkers are so quick to voice directions that often frighten or intimidate the F. However, if you have all $\mathrm{F}$ types, you run the risk of having no conflict, and without some conflict or differences, synergy is not achieved.

In the domains of $\mathrm{J}$ and $\mathrm{P}$, there is need for acknowledgement of strengths of each type, and a plan on how to incorporate these strengths into the group process. Just as one would not ask a person who is not a morning person to be in charge of opening the shop at 5 o'clock in the morning, then one would not ask the P to make the schedule. The $\mathrm{J}$ will keep the team on schedule, while the $\mathrm{P}$ will help the team consider other alternatives in the decision-making process. Since the P is not limited by space and time in their thinking, they present creativity that can enhance the end- product.

\section{CAVEAT TO TEAM ASSIGNMENT}

The MBTI instrument was introduced to all classes with a general discussion of its development and of how it is used. In addition, it is imperative that the following disclaimers are provided the students during this discussion and implementation of the MBTI:

- $\quad$ Morality is not measured by the instrument.

- Deviant behavior is not measured by the instrument.

- $\quad$ Preference does not indicate dominance by a type, and the preference scale index should always be noted.

- $\quad$ Results should seem like a match for your feelings; it should sound like you.

- $\quad$ Superior type does not exist; one type is not superior to any other type.

- $\quad$ Type may vary slightly over time on the preference scale, but will not change.

\section{FIRST PROJECT: RESEARCH AND ORAL PRESENTATION}

For the first project, teams of three to five students were formed with attention to type. Depending on class size, there will be 4-5 teams per class. Students take the MBTI and review their Type and the Types of their team members. 
Students are assigned to find three journal articles online on the MBTI and team building, and to highlight the information that relates to their type, and to the type of each member of the team. They are instructed to become knowledgeable about how they operate in a team and how each of the other team members would work in a team. The grading rubric for Myers-Briggs Assignment is in the appendix (Item 3). The students present their highlighted articles to the instructor one-on-one, and they are required to speak individually and knowledgeable to the instructor on the highlighted article information.

As part of this same assignment, students are instructed on preparing for a small group oral presentation (verbal and non-verbal). The body of the oral presentation contained three parts: background on their type, information on the other types within the team, and an outline or script of how each of the other team members would work on a team project. The introduction for the oral presentation includes information on the MBTI in general, and the conclusion includes a forecast on their team's capacity to achieve team goals. This information is presented in a small team meeting. Each team member evaluates the presentation in terms of verbal and non-verbal skills. The grading rubric for Team Presentation is in the appendix (Item 4).

A note about the logistics of this assignment: Teams should be broken up initially for this part of the project into separate, physical space that can be easily accessed by the instructor. The instructor should visit each group to see that all groups are on task. The students present in their teams, and the team members evaluate each oral presentation. The instructor can combine these two rubrics or use separately, and one grade is instructor generated and the second is team scored.

This assignment educates the students to the MBTI, provides a grade for research, and a grade for an oral presentation. It also sets up some experience working within the team and discussing the individual differences based on the MBTI. The instructor needs to spend time with each team to analyze how the dynamic is working in each team.

\section{SECOND PROJECT: TEAM ASSIGNMENT AND RESEARCH PAPER}

The class is instructed in the use of The American Psychological Association Manual (APA) for research. A unit on research tools and methods is introduced. Students are lectured and directed on researching databases and given specific guidelines on writing and professionally presenting an APA documented research paper. The topic for the research paper is teambuilding or the creation of work teams for business.

The entire process of submitting thesis statement, outline, sources, and rough drafts is directed, along with a timetable for deliverables. As with all research papers, reference articles are required to be copied, with all material quoted or paraphrased, underlined, and submitted with the paper. This is manageable for the instructor, remembering that each class will produce only 4-5 research papers.

A standard rubric for grading the written communication with attention to professional presentation, writing style, amount of research, and APA formatting is used for the research papers. The students evaluate the other team members' performance individually at the end of the project, and this grade is recorded. The guide used for the team evaluation is included in the appendix (Item 4). The team member receives one grade for the term paper; the grade is the same for all members of the team.

Students are in the second team assignment for the semester when they are researching and writing this project, and there is continuation of discussion of MBTI. When the team minutes are submitted to the instructor, the minutes must reflect greater understanding of the team dynamic, and each member's type is included with all communication.

Teams are assigned with attention to type and structured for heterogeneous grouping. A discussion of team formation and the four stages of team development: storming, forming, norming, and performing is presented. It is explained that most teams will not reach the highest evolution of the team experience, but they may still produce a superior product, roles are assigned within the teams. There is mutual agreement on team roles between the 
instructor and the team members: facilitator, harmonizer, record/time keeper, presenter or reporter, leader. The roles can be exchanged and kept fluid during the work process with the agreement of the members of the team. One person may at one time perform more than one function. At some time, everyone may serve in the role of harmonizer or may have harmonizing as part of their role at all time

The teams are given forms for recording team meetings and attendance. The students are also asked to include in the team minutes experiences that occurred relating to their understanding of the MBTI. After each team meeting, these forms are completed and e-mailed to the instructor, and the instructor responds to the e-mails of each team. The record keeper forwards the instructor's correspondence to all members of the team.

\section{CONCLUSION}

Understanding one's own personality type and the type of other team members contributes to a higher learning and is an essential factor in successful team performance and outcomes. The model for team composition presented in this paper will aid in the formation of successful work teams in the classroom and will serve the students well as they enter the work force. The current literature and the results of this research indicate that diversity and balance in team members' type are essential to produce a superior work product.

My experience is somewhat different than most literature indicates in regard to how students really feel about being involved in a team process. Typically, students are not happy about working in teams and are often vocal about the inequities. They think initially that it takes too much time. Stronger students see themselves carrying most of the workload in the project. The use of the MBTI changes how students see themselves and how they see other students. The work product of teams is enhanced, and some of the hatred and dread of teamwork is eliminated. It is essential to make the link for the students that assignment to and work in a team is not an option in the business arena.

It is unrealistic that in every case a full team dynamic of storming, forming, norming, performing may happen in a 15-week semester; however, having two team projects with the first being more focused on understanding team dynamics reinforces the use of type as a tool in the team. Students should view conflict or, for example, lack of a plan by the second project session, as the result of type difference and be able to make the necessary shifts in dynamics to achieve the goals.

The classroom assignments presented are intended as tools for the classroom instructor and can be incorporated easily into team projects. As teachers in any field, it is essential that we stress to students that they do self-examination to understand who they are and help them develop a clear picture of what they can contribute in the classroom and beyond. Administering the MBTI and using the type information to form teams is a major step in this process of forecasting stronger team outcomes in the classroom.

On a more lofty level, for us to move forward as a society, we must begin in the classroom. It is interesting to note that the mother-daughter team, who created the MBTI that we use today in the classroom and the boardroom, believed that their instrument, if utilized properly and widely, could bring about world peace. This is admittedly a rather lofty ideal for just a test created by psychologists; but I have seen the impact on the work product and relationships that can be achieved in the business arena and, now, in the classroom.

I welcome dialogue and sharing; please e-mail your questions, disappointments, and successes.

All documents listed in the Appendix are on the Web at: ftp://users.ju.edu. 


\section{REFERENCES}

1. Bayen, R. (1995). The Myers-Briggs type Indicator: a critical review and practical guide, Chapman \& Hall, New York.

2. Brightman, H. J. (ND). Georgia State University Master Teacher Program: On Learning Styles. Retrieved March 18, 2006 from the Master Teacher Program/Improving University Level Teaching and Learning. Web site: www.gsu.edu/ dschjb/wwwmbti.html.

3. Coby, V. \& Lewis, S. (September 2000). Using the Experiential Learning Theory and the Myers-Briggs Type Indicator in Teaching Business Communications. Business Communication Quarterly, 63 (3), 59-48.

4. Culp, G. \& Smith, A. (2001). Understanding psychological type to improve project team performance. Journal of Management Engineering, 17 (1), 24-33.

5. Dilworth L. \& Richter, K. (1995). QFD and personality type: The key to team energy and effectiveness. Industrial Engineering. 27 (2), 57-61.

6. Hammer, A.L. \& Huszczo, G..E. (1996). Teams. In A, L. Hammer (Eds). MBTI applications: A decade of research in the Myers-Briggs Type Indicator (pp.81-103). Palto Alto, CA: Consulting Psychologists Press, Inc.

7. Muchinsky, P. M., and Monahan, C. J. (1987). What is person-environment congruence? Supplementary versus complementary model of fit. Journal of Vocational Behavior, 31, 268-277.

8. Myers, I. B., McCaulley, M. H., Queck, N. L. \& Hammer, A. L. (1998). MBTI manual: A guide to the development and use of the Myers-Briggs Type Indicator $\left(3^{\text {rd }}\right.$ ed.) Palto Alto, CA: Consulting Psychologists Press.

9. Neuman, G..A. Wagner, S.H., and Christiansen, N.D. (1999). The relationship between work-team personality composition and the job performance of teams. Group \& Organizational Management, 24(1), 28-45.

10. Varvel, T., Adams, S.G., Pridie, S.J., \& Ruiz Ulloa, B.C. (October, 2004). Team Effectiveness and Individual Myers-Briggs Personality Dimensions. Journal of Management in Engineering, 20 (4), $141-146$.

\section{NOTES}

